\title{
Analysis of E-mental Health Research: Mapping the Relationship between Information Technology and Mental Healthcare
}

tatsawan timakum

Chiang Mai Rajabhat University

Min Song ( $\square$ min.song@yonsei.ac.kr)

Yonsei University

Qing Xie

Yonsei University

\section{Research Article}

Keywords: E-mental health, E-health, E-therapies, Mental health, Text mining

Posted Date: September 3rd, 2021

DOl: https://doi.org/10.21203/rs.3.rs-741015/v1

License: (c) (i) This work is licensed under a Creative Commons Attribution 4.0 International License.

Read Full License

Version of Record: A version of this preprint was published at BMC Psychiatry on January 25th, 2022. See the published version at https://doi.org/10.1186/s12888-022-03713-9. 


\section{Abstract}

Background: E-mentalhealthcare is the convergence of digital technologies with mental health services. It has beendevelopedto fill a gap in healthcare for people who need mental wellbeing support and may never otherwise receive psychological treatment.This study aimed to apply text mining techniques to analyze the huge data of e-mental health researches and to report on research clusters and trends as well as the co-occurrence of biomedical and the use of information technology in this field.

Methods: The e-mentalhealth research data was obtainedfrom 3,663 bibliographicrecords from Web of Science (WoS)and 3,172 full-text articlesfrom PubMed Central (PMC). The text mining techniques utilized for this study includedbibliometric analysis, information extraction, and visualization.

Results: The e-mental health research topic trendsprimarily involvede-health care services and medical informatics research. The clusters of research comprise 16 clusters, which refer to mental sickness, ehealth, diseases, IT, and self-management. Based onthe information extraction analysis, in the biomedical domain, a "depression" entity was frequently detected and it pairs with other entities in the network with a betweenness centrality weighted at 0.046869 (eg. depression-online, depression-diabetes, depression-measure, and depression-mobile). The IT entity-relations of "mobile" were the most frequently found(weighted at 0.043466 ). The top pairs are related to depression, mobile health, and text message.

Conclusions: E-mental health research trends focused on disease related-depression and using IT for treatment and prevention, primarily via online and mobile devices. Producing Al and machine learning are also being studied for e-mental healthcare. The results illustrate that physical sickness is likely to cause a mental health problem and identify the IT that was applied to help manage and mitigate mental health impacts.

\section{Background}

The demand for mental health services has been growing globally in recent years. Mental health conditions arise not only as a result of genetic factors and life circumstances, but also other illnesses. This is especially a problem for people with chronic diseases such as cancer, diabetes, and high blood pressure [1]. Lower social and economic barriers, among other forces, are leading to more significant numbers of individuals coming forward for help with mental illness [2]. Because the mental health service resources have not been progressing to meet the growing demand, service capacity has been under pressure [3-4]. This has resulted in longer waiting times for people in need of support as well as an extensive treatment gap reflected in the high number of people who never receive any treatment.

Digital health is an interdisciplinary field that integrates digital technologies with health, healthcare, and society to enhance the efficiency of healthcare delivery and make medicines more personalized and precise. As part of this, electronic mental (E-mental) health care has been developed to support mental wellbeing by preventing mental illness and the need for psychological treatment [5]. It is part of a solution to directly help individuals in need by utilizing information and communication technology (ICT) via the 
internet [6-7]. E-mental health care includes digital technology-based treatments and new media such as web-based interventions, mobile phone-based interventions, text message service, email interventions, and virtual reality-based interventions for mental health self-management and the distribution of health promotion, screening, prevention, and treatment [8]. Moreover, it can improve the health care of patients, provide professional education through e-learning, and contribute to electronic research in mental health care [9] focusing on cognitive behavioral therapy (CBT) [10].

Additionally, it can collect individual data to detect mental health symptoms and develop personalized programs that can overcome barriers to seeking help [11]. The tailored treatments may include supportive feedback, CBT, psychoeducation, and acceptance commitment therapy [5]. In recent years, e-mental health treatment programs have incorporated various applications and technologies for smartphone users that are available to the public and can also be found via the NHS applications library which is provided by NHS in England (https://www.nhs.uk/apps-library/category/mental-health/). These applications are assessed against a range of NHS standards. The use of IT for e-mental health support such as mobile devices and web applications which are the new way to assist a doctor in screening, assessing, monitoring, and delivering treatment interventions as well as to support the patients for access care [12].

E-mental health has been implemented across various sciences, such as the medical, psychological, information, media, and technology fields, and it has been an area of increasing interest among researchers. Most of the existing research articles have explicitly studied the use of technology in mental health services for specific diseases and have manually reviewed a limited number of documents [10, 13-14]. For example, one study investigated different types of e-mental health self-management interventions [8]. Other studies analyzed the effectiveness of technology-based self-help therapies and behavioral interventions such as computerized treatment for addictive disorders [5], online treatment for depression [10], and web-based interventions for alcoholism [15]. Another study analyzed the benefits and negative impact of social network services on the internet [16]. Although one study examined a survey of e-therapies and proposed to document the range of web and smartphone apps used and recommended for mental conditions and mental health services, this study further required the evidence base for the use of apps for service provision [6].

Toward identifying and visualizing the key attributes of e-mental health, this study proposes to increase the understanding of this research field and the IT for e-mental health as well as to support information for developing a better device for mental health interventions. This study aimed to examine research clusters and trends, including examining the entities and their connections between the biomedical domain (diseases, symptoms, and treatments) and IT. In particular, the present study was designed to answer the following questions: 1) What are the research clusters and trends in e-mental health? 2) What kind of IT is being used in e-mental health? 3) What are the common diseases connected with mental health conditions, and how can IT be used for treatment?

\section{Related Work}


Bibliometrics is a quantitative statistical analysis approach that has been widely used in the study of scientific citations in an academic communication system [17]. It has also been used to explore research topics and trends and has been used to evaluate the productivity of authors and cooperative networks in specific fields [18]. Using this method, the collaboration pattern between authors, institutions, and publishers can be captured to better understand global trends and discover the research frontiers [19]. Bibliometrics has been widely utilized in interdisciplinary research to identify hidden or emerging subjects [20] by analyzing a specific research domain and emerging trends. Mapping science helps depict the knowledge structure in scientific networks and discover growing areas in the discipline. In the case of ehealth, these include health informatics [21-22], international mobile health research [23], and electronic health and telemedicine [24].

\section{Information Extraction}

Information extraction (IE) is a text mining technique to pull useful information from text documents. It is part of a field of Natural Language Processing (NLP) that is used for tasks including Named Entity Recognition (NER) and Relation Extraction (RE) [25]. The NER system recognizes a named entity that occurred in the text, such as the name of a person, organization, or specific category. The RE system detects and classifies a relationship between entities in the text. The shared functions in the information extraction approach have significantly contributed to identifying patterns of knowledge in fields such as health and biomedicine. Several tools have been developed to analyze the relations (connections) between entities. Some of the relationship entities that have been studied include drugs and side effects [26], diseases and drugs [27-29], and drugs and genes [30].

Network Analysis and Visualization

Network analysis is a method derived from network theory. It has emerged from the field of computer science to illustrate the influence of social networks [31] and allows researchers to describe relationships between entities [32]. Social network analysis has been applied in several fields including the science of citation, which was presented in graph theory [33]. Concept graphs consist of sets of nodes and edges that are used to represent text documents [34]. The concept graphs create visual links and measure the impact of each node based on their pairs in a network. This technique determines which terms are used as a bridge in a network. Therefore, it is necessary to calculate metrics such as the weighted degree of nodes [35] and betweenness centrality [36], which are crucial to analyzing the co-occurrence network.

\section{Methods}


The data used for visualizing the research clusters and time series were downloaded under the research topic of E-mental Health from Web of Science (WoS) in bibliographic records, and the data for information extraction was obtained from full-text papers from PubMed Central (PMC) databases. Both datasets were retrieved on December 16, 2019.

We included "ehealth" $O R$ "mhealth" in the search words as follows because it is widely used for the electronic health domain, therefore, we included these words for reaching all related data of electronic mental health. However, to get appropriated data for our study, we limited our searching criteria by using $A N D$ "mental" OR "emental."

The WoS data was collected by limiting the topic search to "eHealth" $O R$ "mHealth" $A N D$ "mental" $O R$ "eMental", selecting English as the language, and limiting the document types to "Article $O R$ Review $O R$ Meeting Abstract $O R$ Editorial Material OR Proceeding paper." We also selected the timespan of all years, and the collection indexes included were the Science Citation Index Expanded, Social Science Citation Index, Arts and Humanities Citation Index, and Emerging Sources Citation Index. The WoS dataset included 3,663 records (Bibliographic record).

For the PMC data, the keywords search were limited to "emental" [Body - All Words] OR "ehealth" [Body All Words] OR "emental health" [Body - All Words] OR "mhealth" [Body - All Words] AND "mental" [Body - All Words]. The full-text results included 3,172 records (full-text XML format).

\section{Data processing}

The research was designed to analyze the clusters and trends of e-mental health research and extract the entities of biomedical (diseases, symptoms, and treatments) and IT domains and investigate the association of those entities. We also used visualization tools to present the research clusters and the cooccurrence of entities as a graph.

First, a bibliometric analysis was applied to get a comprehensive understanding of the clusters of emental health research as well as a time series and the trends by analyzing the WoS data. The WoS analysis tool (Clarivate Analytics) was used to observe the research trends, and Citespace.5.5.R2 [37]was used to examine and visualize the clusters of e-mental health and time-series of them. The period from 1990 to 2019 was selected for the study. The bibliography data from WoS was analyzed based on collaboration relationships using a reference and cited author. The sources were represented by the title, abstract, author keywords (DE), keywords plus (ID), and shown a node type by the term and keyword. The top 50 most cited or occurring items were selected for visualization from each year slice. This process was applied to answer the RQ. 1.

Second, entity and relation extraction was used to identify the biomedical and IT entities and their connections in the full-text papers of the PMC using the PKDE4J 2.0 knowledge discovery tool [38]. This system integrates dictionary-based entity extraction and rule-based relation extraction. To identify the entities of e-mental Health, four types of entities (dictionaries)were selected, including "Information 
Technology", "Disease”, “Symptom”, and "Treatment”, which were used as inputs for the tool. To use these dictionaries, we considered a description of self-management [39] which relates to the management of symptoms, treatments, physical and mental conditions (diseases). The biomedical dictionaries were created from clinical healthcare terminology based on the National Library of Medicine's controlled vocabulary thesaurus (MeSH) [40] and clinical terms [41]. The IT lexicon was collected from IT resources, such as the TechTerms [42] and Computer Hope [43], which provides support related to the internet, software, artificial intelligence, cell phones, internet, smartphones, sound, video, IT security, etc. A summary of the dictionary data is displayed in Table 1. In addition, the system incorporated biomedical verbs, which were extracted from the unified Medical Language System [44]. This analysis was provided for RQ. 1 and RQ. 2.

Table 1

Dictionaries for entity analysis

\begin{tabular}{|lll|}
\hline Dictionary & $\begin{array}{l}\text { Word } \\
\text { count }\end{array}$ & Word examples \\
\hline $\begin{array}{l}\text { Information } \\
\text { Technologies }\end{array}$ & 39,447 & $\begin{array}{l}\text { videoconferencing, image, visual information, mobile internet } \\
\text { technologies, mobile Health }\end{array}$ \\
\hline Diseases & 71,234 & $\begin{array}{l}\text { breast cancer, acute asthma, eating disorders, severe asthma, } \\
\text { bipolar }\end{array}$ \\
\hline Symptoms & 387 & $\begin{array}{l}\text { tightness, phobia, nausea, inflammation, fatigue } \\
\text { radiation, surgery, behavior assessment, medical photography, } \\
\text { breast pneumocystogram }\end{array}$ \\
\hline Treatments & 7,800 & \\
\hline
\end{tabular}

The data pre-processing [38] included abbreviation resolution, tokenization, sentence splitting, POS tagging, lemmatization, and string normalization. These techniques were applied to perform a sentencelevel analysis of both datasets. They were then processed through Named Entity Recognition (NER), which is a dictionary-based approach. The NER consists of N-gram matching, approximate string match, regex NER, candidate entity filtering, and labeling. Lastly, the data was delivered to post-preprocessing and rule generation to be assigned an entity name and entity type.

After extracting and receiving entities and relations results from 3,172 full-text papers, the relationships were used to construct two different networks of entities to be analyzed. First, a network of four entity types and their connections were examined to provide an overview and visualize the prominent pairs in the PMC dataset. Second, a graph of common diseases was created to illustrate the connections between entities of IT, symptoms, and treatments. The nodes (entities) and edges (relations/connections) were evaluated based on betweenness centrality and weight degree. Later, the Gephi 0.9.2 software [45] was used to visualize those networks. An overview of the data processing is shown in Fig. 1.

\section{Results}

\section{E-mental Health Research Trends}


Based on the WoS data analysis, the first publication related to electronic health (e-health) research, indexed by the Clarivate Analytics tools, was published in 2000. It investigated the impact of the internet on electronic patient records. The ethics of e-health was an area of major concern when this research field was emerging. In 2019, telehealth services, especially mobile apps for mental health and health monitoring, were mentioned frequently.

As shown in Fig. 2, the number of studies in e-mental health research has been increasing steadily. In 2015 in particular, there was a significant change in the number of publications related to e-mental health, rising to 359 records that year and peaking at 789 records in 2019.

Research in the field of e-mental health is continually increasing (Fig. 2). The results of this study indicate that this research area began in 2000 with a study on electronic patient records using an internet-based approach [46] as well as a study on the ethics of electronic health[47]. In 2006, e-health research regarding eHealth literacy was prominent. The most cited research paper was on eHealth literacy skills for consumer health [48]. This upward trend in e-health research continued and reached the highest number of studies in 2015. Research included topics such as internet resources for health care[49], mobile apps[50], mobile phone sensor[51], and web 2.0 [52]. For example, one study focused on treatment delivery via mobile apps for bipolar disorder [53]. From 2019, telehealth services, especially mobile and smartphone applications for mental health and health monitoring, were well-established in this research field. A telerehabilitation study [54] was the most cited. These results reflect the growing research trends in e-mental health care.

Moreover, the research area examination by WoS categories analysis shows that the top-ranking field for published research papers associated with e-mental health was health care sciences services (1366 records), followed by medical informatics (1106 records), and computer science (399 records). Other related areas included public health, psychiatry, nursing, telecommunication, and biomedical social sciences as shown in Table 2. 
Table 2

Top research areas under the e-mental health study using Clarivate Analytics tools

\begin{tabular}{|ll|}
\hline Research Areas & Records \\
\hline Health care sciences services & 1366 \\
\hline Medical informatics & 1106 \\
\hline Computer science & 399 \\
\hline Public environmental occupational health & 361 \\
\hline Psychiatry & 294 \\
\hline Psychology & 287 \\
\hline General internal medicine & 177 \\
\hline Oncology & 168 \\
\hline Engineering & 142 \\
\hline Nursing & 104 \\
\hline Information science library science & 92 \\
\hline Telecommunications & 82 \\
\hline Biomedical social sciences & 65 \\
\hline Cardiovascular system cardiology & 62 \\
\hline Research experimental medicine & 60 \\
\hline Neurosciences neurology & 54 \\
\hline Rehabilitation & 53 \\
\hline Social sciences other topics & 53 \\
\hline Endocrinology metabolism & 50 \\
\hline Education educational research & 49 \\
\hline
\end{tabular}

\section{Mapping the Clusters of E-mental Health Research}

According to the bibliographic analysis, the most frequent document type in the co-citation network was articles, with a total of 10,834 items. This was followed by review papers (2,211 items), early access articles (1,140 items), meeting abstracts, editorial material, and reviews of early access. The network included 1,392 nodes and 2,784 edges.

The system detected meaningful research clusters from the co-citation network in a total of 16 groups (Fig. 3). The keywords identified in the e-mental health research were divided into 16 clusters through 
cluster analysis. The cluster name was determined based on the keywords in the corresponding cluster, as shown in Table 3. The full cluster analysis is available via the DOI link; please refer to the Appendix 1. Only the top ten words per group, the size of the cited references, and the mean year of each cluster are shown. Cluster \#0, "depression", is the largest research cluster with 82 members, and this cluster is associated with mental health, noncommunicable diseases, breast cancer survivors, and cognitivebehavioral. This cluster was followed by the \#1 "mhealth," cluster with 74 articles, and a focus on mental health, user engagement, alcohol consumption, mobile apps, and e-mental health. Cluster \#2, "health literacy", had 56 papers. It is related to the theory and technique of psychological knowledge evaluation, shown in terms of psychometrics, classical test theory, item response theory, and social support.

The rest of the clusters are \#3 "smoking cessation," \#4 "physical activity," \#5 "obesity," \#6 "telehealth," \#7 "older adults," \#8 "cancer," \#9 "health information," \#10 "psychosis," \#11 "usability testing," \#12 "msm," \#13 "artificial intelligence," \#14 "self-management," and \#15 "ehealth." Some clusters refer to mental disorders and related diseases and symptoms including smoking cessation, obesity, cancer, and psychosis, which are associated with mental health challenges. Some clusters represent a treatment using IT for self-management, such as the clusters for physical activity, telehealth, health information, self-management, and ehealth. Other clusters represent usability design for the participants, as demonstrated by the cluster for usability testing and artificial intelligence. The most common target demographics are elderly people and men who have sex with men (MSM). 
Table 3

Top ten words per research cluster

\begin{tabular}{|c|c|c|c|}
\hline Cluster-ID & $\begin{array}{l}\text { Size } \\
\text { (\# } \\
\text { members) }\end{array}$ & $\begin{array}{l}\text { Mean } \\
\text { year }\end{array}$ & Top terms (LSI) \\
\hline $\begin{array}{l}\text { \#0 } \\
\text { depression }\end{array}$ & 82 & 2012 & $\begin{array}{l}\text { mental health; noncommunicable diseases; developing } \\
\text { countries; behavior change; consort ehealth; reporting } \\
\text { standards; breast cancer survivors; commitment therapy; } \\
\text { acceptance; cognitive behavioral therapy }\end{array}$ \\
\hline \#1 mhealth & 74 & 2015 & $\begin{array}{l}\text { mental health; user engagement; hazardous alcohol use; } \\
\text { mobile apps; computer game; digital tools; rheumatology; } \\
\text { young adult; e-mental health; noncommunicable diseases }\end{array}$ \\
\hline $\begin{array}{l}\text { \#2 health } \\
\text { literacy }\end{array}$ & 56 & 2013 & $\begin{array}{l}\text { health literacy; psychometrics; classical test theory; item } \\
\text { response theory; adolescents; cancer survivors; digitization; } \\
\text { nursing student; breast neoplasms; social support }\end{array}$ \\
\hline $\begin{array}{l}\text { \#3 smoking } \\
\text { cessation }\end{array}$ & 53 & 2013 & $\begin{array}{l}\text { mobile health; telemedicine; health care evaluation } \\
\text { mechanisms; interviews; Topic; data collection; inhalation } \\
\text { therapy; smartphone; digital behavior change intervention; } \\
\text { mobile phones }\end{array}$ \\
\hline $\begin{array}{l}\text { \#4 physical } \\
\text { activity }\end{array}$ & 47 & 2012 & $\begin{array}{l}\text { physical activity; controlled trial; chronic disease; healthy } \\
\text { eating; lifestyle intervention; health behaviours; self-regulation; } \\
\text { measurement; sedentary behaviour; public health }\end{array}$ \\
\hline \#5 obesity & 46 & 2014 & $\begin{array}{l}\text { telemedicine; digital health; hypertension prevention; medical } \\
\text { technology; e-mental health; consort ehealth; reporting } \\
\text { standards; relationship; mobile application; communication }\end{array}$ \\
\hline \#6 telehealth & 42 & 2014 & $\begin{array}{l}\text { telemedicine; consumer satisfaction; ehealth services; health } \\
\text { information exchange; interoperability; smartphone; } \\
\text { healthcare system; telehealth technology; underserved area; } \\
\text { mental health }\end{array}$ \\
\hline $\begin{array}{l}\text { \#7 older } \\
\text { adults }\end{array}$ & 40 & 2009 & $\begin{array}{l}\text { mental health; evidence-based treatment; mobile applications; } \\
\text { health technology; technophilia; mobile apps; information } \\
\text { technology; telehealth technology; frontline care; health equity }\end{array}$ \\
\hline \#8 cancer & 28 & 2015 & $\begin{array}{l}\text { life; health-related quality; cancer survivors; patient-reported } \\
\text { outcome measures; implementation; cognitive behavioral } \\
\text { therapy; erectile function; mental health; measurement } \\
\text { properties; prostate cancer survivors }\end{array}$ \\
\hline $\begin{array}{l}\text { \#9 health } \\
\text { information }\end{array}$ & 28 & 2013 & $\begin{array}{l}\text { health information; healthcare professional; personal } \\
\text { experiences; age difference; adult; unified theory; user } \\
\text { acceptance; cultural sensitivity; health education; ehealth } \\
\text { access }\end{array}$ \\
\hline $\begin{array}{l}\# 10 \\
\text { psychosis }\end{array}$ & 23 & 2012 & $\begin{array}{l}\text { digital health; mobile health; consumer protection; advertising } \\
\text { standards; digital mental health interventions; digital health } \\
\text { applications; think-aloud test; mental health; controlled } \\
\text { intervention trial; nurse-patient relationships }\end{array}$ \\
\hline
\end{tabular}




\begin{tabular}{|llll|}
\hline Cluster-ID & $\begin{array}{l}\text { Size } \\
\text { (\# } \\
\text { members) }\end{array}$ & $\begin{array}{l}\text { Mean } \\
\text { year }\end{array}$ & Top terms (LSI) \\
\hline $\begin{array}{l}\text { \#11 usability } \\
\text { testing }\end{array}$ & 16 & 2010 & $\begin{array}{l}\text { mental health; iterative prototype testing; ambulatory } \\
\text { biofeedback; mobile health; design; design science; borderline } \\
\text { personality disorder; emotional awareness; user; think-aloud } \\
\text { test }\end{array}$ \\
\hline $\begin{array}{l}\text { \#12 msm } \\
\text { \#13 artificial } \\
\text { intelligence }\end{array}$ & 11 & 2013 & $\begin{array}{l}\text { noncommunicable diseases; health policy; qualitative } \\
\text { research; disease management; sub-saharan africa; } \\
\text { implementation science; digital divide; health information; } \\
\text { medication adherence; scalability }\end{array}$ \\
\hline $\begin{array}{l}\text { \#14 self- } \\
\text { management }\end{array}$ & 5 & 2015 & $\begin{array}{l}\text { digital health; artificial intelligence; mobile health; government } \\
\text { regulation; medical informatics; conversational agents; global } \\
\text { cause; prenatal education; deep learning; doctor-patient } \\
\text { relationship }\end{array}$ \\
\hline \#15 ehealth & 5 & 2008 & $\begin{array}{l}\text { self-management; kidney transplantation; life; physical } \\
\text { activity; quality; colorectal cancer survivors; computer literacy; } \\
\text { cancer survivorship; breast cancer survivors; health literacy }\end{array}$ \\
\hline
\end{tabular}

\section{IT and Biomedical Entities and Relations}

The PKDE4J software categorized entities into four types: IT, treatment, disease, and symptom. Then, the relation extraction process was performed to detect co-occurrences between two entities within a sentence of the data corpus. Table 4 shows the results of the named entity extraction. The most frequently occurring entity was IT, with 667,291 entities and 2,290 different entity names. This was followed by the treatment entity $(106,519)$, disease $(78,622)$, and symptom $(17,474)$. The disease entity had the most entity names (2,765), whereas the symptom entity had only 106 entity names. The top 30 entity names for each entity type are shown in Table 7-10, along with their influence degree in a network.

Table 4

Entity extraction results

\begin{tabular}{|lll|}
\hline Entity type & Entity counts & Entity names \\
\hline IT & 667,291 & 2,290 \\
\hline Treatment & 106,519 & 787 \\
\hline Disease & 78,622 & 2,765 \\
\hline Symptom & 17,474 & 106 \\
\hline
\end{tabular}

After extracting the entities, the system determined the connections between any two entities found in the same sentence and connected them with a relation verb. Table 5 displays the relation extraction results with the total numbers of co-occurrences. The connection between IT and IT was perceived the most 
frequently ( 777,788 counts). However, we did not focus on this co-occurrence since the study aimed to investigate the association of IT with diseases, symptoms, and treatments. The analysis shows that the co-occurrence of IT and treatments occurred 125,199 times, followed by IT and diseases $(96,732)$ and IT and symptoms (18081).

Table 5

Relation extraction results

\begin{tabular}{|ll|}
\hline Entity pairs & Total co-occurrences \\
\hline Technology | Technology & 777,788 \\
\hline Technology | Treatment & 125,199 \\
Treatment | Technology & \\
\hline $\begin{array}{l}\text { Technology | Disease } \\
\text { Disease | Technology }\end{array}$ \\
\hline $\begin{array}{l}\text { Technology | Symptom } \\
\text { Symptom | Technology }\end{array}$ \\
\hline
\end{tabular}

Examples of entity pairs and their relation verbs are shown in Table 6. The relation extraction process identifies the co-occurrence of entities at the sentence-level, in which the entity extraction module has extracted two or more entities. The relationship analysis module takes a list of verbs and nominalization words that are used to identify relationships of interest. For instance, the Entity 1 "text messaging" (IT type) connects to Entity 2 "smoking cessation" (Disease) with the relation verb "target," which were extracted from the same sentence. This result was detected from the following sentence in the dataset.

"Thus, SMS text messaging might be an appropriate way to target smoking cessation in low SES and African American smokers".

Table 6

Entity and relation extraction examples

\begin{tabular}{|lllll|}
\hline Entity $\mathbf{1}$ & Entity type & Entity $\mathbf{2}$ & Entity type & Relation verb \\
\hline text messaging & Technology & smoking cessation & Disease & target \\
\hline Twitter & Technology & bipolar & Disease & co-occur \\
\hline consultation & Treatment & email & Technology & co-occur \\
\hline discussion & Treatment & text messaging & Technology & co-occur \\
\hline depression & Symptom & smartphone & Technology & co-occur \\
\hline depression & Symptom & cognitive behavioral therapy & Technology & use \\
\hline
\end{tabular}

As shown in Table 6, the PKDE4J system extracted two entities (entity 1 and entity 2) found in the same sentence and they were connected with a relation verb, and then it attributed the type of entity. The 
system reported a relation verb as a "co-occur" in cases of no relation (verb), the system treated that sentence as a juxtapose, which means that the entities simply co-occurred in the sentence.

The results of entity and relation extraction were further employed in the network analysis to determine the degree of each entity (node) and relation (edge), which are displayed as a graph for easier interpretation.

\section{E-mental Health Entities Network Analysis}

The entity and relation extraction results were passed into a graphML formatting process to create a network and were exported to Gephi for visualization. The network was evaluated by betweenness centrality to produce a bigger graph, which combines all of the entities, relations, and weighted degrees for a specific network, such as a specific disease with IT. Betweenness centrality for a node represents the degree to which the nodes are mutually connected [55]. Thus, a node with higher betweenness centrality will be more important than other nodes because more information will pass through that node. In other words, the entities weighted higher indicate a higher impact.

\section{IT and Biomedical Entities Network}

The network was processed according to the shortest path between each entity pair to produce the graph (Fig. 4). The network shows the entities and connections of four entity types, including technology (used for IT), disease, symptom, and treatment. The network is an indirect graph, which integrates the related research of e-mental health in a total of 7,025 nodes and 105,621 edges. Each node refers to the extracted entities from 3,172 full-text papers, and the edge indicates the connections between nodes. The top 30 highest ranked nodes based on betweenness centrality are reported for each entity type in Table 7-10.

The graph demonstrates that among the 7,025 nodes and 105,621 edges, "depression" frequently pairs with other entities in the network. This was the biggest node with a betweenness centrality weighted at 0.046869 , followed by "mobile" (weighted at 0.043466), "cancer" (weighted at 0.041167), and "screening" (weighted at 0.028047). The "depression" node had a high influence on other nodes, including "cancer," "diabetes," "mobile," "online," "measures," "content," "screening," "discussion," etc.

Moreover, the results indicate that the technology (IT) nodes are strongly co-occurred with "mobile," "measure," "online," "content," "video," "protocol" (communication protocol), and "security." The IT nodes link to various entities. For instance, the node "measures" is connected to not only the entity type itself ( mobile, online, content, smartphone, and interactive) but also with disease entities (cancer, diabetes, secondary, hypertension, arthritis, stroke, and blood pressure) and symptom entities (depression, fatigue, and discharge,). Moreover, it is linked to treatment nodes, including "screening," "surgery," "discussion," "measurement," "examination," "advice," and "consultation."

The treatment entity type is frequently represented by the entities "screening," "surgery," "discussion," "measurement," and "examination". As displayed in the graph, "screening" is co-occurred with other nodes 
(diseases, symptoms, and technology) and connects with diseases such as cancer, diabetes, and hypertension). 
Table 7

Top 30 Technology entities ranked by betweenness centrality

\begin{tabular}{|ll|}
\hline Technology entities & Betweenness centrality \\
\hline mobile & 0.043466 \\
\hline measures & 0.03651 \\
\hline online & 0.035715 \\
\hline content & 0.029963 \\
\hline mobile phone & 0.020602 \\
\hline phone & 0.017235 \\
\hline video & 0.016899 \\
\hline protocol & 0.016559 \\
\hline security & 0.015979 \\
\hline database & 0.014449 \\
\hline search & 0.013197 \\
\hline network & 0.01292 \\
\hline sites & 0.012854 \\
\hline collaboration & 0.012822 \\
\hline interactive & 0.012583 \\
\hline smartphone & 0.012131 \\
\hline website & 0.012016 \\
\hline remote & 0.011993 \\
\hline email & 0.011864 \\
\hline signal & 0.008645 \\
\hline telephone & 0.00823 \\
\hline mobile health & 0.007792 \\
\hline social media & 0.007778 \\
\hline virtual & 0.007588 \\
\hline sensor & \\
\hline media & 0.0693 \\
\hline
\end{tabular}




\begin{tabular}{|ll|}
\hline Technology entities & Betweenness centrality \\
\hline mobile phones & 0.006405 \\
\hline algorithm & 0.006144 \\
\hline transmission & 0.005924 \\
\hline randomized controlled trial & 0.005882 \\
\hline
\end{tabular}


Table 8

Top 30 Treatment entities ranked by betweenness centrality

\begin{tabular}{|ll|}
\hline Treatment entities & Betweenness centrality \\
\hline screening & 0.028047 \\
\hline surgery & 0.022244 \\
\hline discussion & 0.017118 \\
\hline measurement & 0.013998 \\
\hline examination & 0.010859 \\
\hline advice & 0.007979 \\
\hline consultation & 0.007741 \\
\hline counseling & 0.005387 \\
\hline prescription & 0.005225 \\
\hline observation & 0.004164 \\
\hline injection & 0.003366 \\
\hline meetings & 0.003202 \\
\hline clinical trial & 0.003072 \\
\hline expression & 0.002974 \\
\hline chemotherapy & 0.002935 \\
\hline adjustment & 0.00276 \\
\hline acupuncture & 0.002377 \\
\hline risk assessment & 0.001961 \\
\hline patient education & 0.00194 \\
\hline notifications & 0.001752 \\
\hline case management & 0.001569 \\
\hline stress management & 0.001488 \\
\hline immunization & 0.001425 \\
\hline viral load & 0.001253 \\
\hline psychoeducation & 0.001195 \\
\hline radiation & 0.000626 \\
\hline
\end{tabular}




\begin{tabular}{|ll|}
\hline Treatment entities & Betweenness centrality \\
\hline relapse prevention & 0.000563 \\
\hline health assessment & 0.000539 \\
\hline physical therapy & 0.000528 \\
\hline scanning & 0.000519 \\
\hline
\end{tabular}


Table 9

Top 30 Disease entities ranked by betweenness centrality

\begin{tabular}{|c|c|}
\hline Disease entities & Betweenness centrality \\
\hline cancer & 0.041167 \\
\hline diabetes & 0.039699 \\
\hline secondary & 0.018623 \\
\hline stroke & 0.017603 \\
\hline hypertension & 0.015674 \\
\hline arthritis & 0.012551 \\
\hline blood pressure & 0.010385 \\
\hline obesity & 0.008463 \\
\hline breast cancer & 0.00732 \\
\hline fever & 0.007283 \\
\hline asthma & 0.007114 \\
\hline dementia & 0.006455 \\
\hline diabetes mellitus & 0.006232 \\
\hline infections & 0.005956 \\
\hline conventional & 0.005703 \\
\hline hepatitis & 0.00563 \\
\hline smoking cessation & 0.005504 \\
\hline chronic diseases & 0.005452 \\
\hline heart failure & 0.005305 \\
\hline peripheral & 0.00495 \\
\hline injury & 0.004899 \\
\hline schizophrenia & 0.004834 \\
\hline tuberculosis & 0.004755 \\
\hline trauma & 0.004692 \\
\hline chronic disease & 0.003998 \\
\hline injuries & 0.003996 \\
\hline
\end{tabular}




\begin{tabular}{|ll|}
\hline Disease entities & Betweenness centrality \\
\hline bipolar & 0.003833 \\
\hline chronic pain & 0.003811 \\
\hline type 2 diabetes & 0.003218 \\
\hline heart disease & 0.003002 \\
\hline
\end{tabular}


Table 10

Top 30 Symptom entities ranked by betweenness centrality

\begin{tabular}{|ll|}
\hline Symptom entities & Betweenness centrality \\
\hline depression & 0.046869 \\
\hline fatigue & 0.010418 \\
\hline discharge & 0.007438 \\
\hline insulin & 0.007111 \\
\hline insight & 0.00292 \\
\hline migraine & 0.001742 \\
\hline orientation & 0.00143 \\
\hline intermittent & 0.001223 \\
\hline constant & 0.000688 \\
\hline burning & 0.000664 \\
\hline necrosis & 0.000598 \\
\hline swelling & 0.000406 \\
\hline breathlessness & 0.00034 \\
\hline dysplasia & 0.000298 \\
\hline chest pain & 0.000286 \\
\hline mucosa & 0.000284 \\
\hline scared & 0.000284 \\
\hline tender & 0.00028 \\
\hline fracture & 0.000246 \\
\hline suicidal thoughts & 0.000239 \\
\hline shooting & 0.000188 \\
\hline epidural & 0.000151 \\
\hline neck pain & 0.000119 \\
\hline irritable & 0.000099 \\
\hline intoxication & 0.000092 \\
\hline tingling & 0.000092 \\
\hline
\end{tabular}




\begin{tabular}{|ll|}
\hline Symptom entities & Betweenness centrality \\
\hline irrelevant & 0.000086 \\
\hline hyperactivity & 0.000085 \\
\hline tightness & 0.00007 \\
\hline phobia & 0.000068 \\
\hline
\end{tabular}

A large network of e-mental health entities and relations (IT, diseases, symptoms, and treatments) demonstrates that the biggest node is "depression" (Fig. 4). It is a common mental health symptom that occurs not only in psychosis patients but also with other physical sicknesses.

The technology-related entities most frequently identified in the network were "mobile" and "online,". In addition, the entities of multimedia for self-monitoring and facilitation in therapy were visualized, including "video," "sites," "email," "social media," "virtual," "image," and "text messages". Smart devices were also frequently identified in the e-mental health network. Examples of these entities include "mobile phones," "smartphones," "sensors," and "real-time," as well as operating system entities such as "protocol," "remote," "algorithm", and "android". Technology-based self-help has been proposed for effective and lowcost interventions for disease management and therapy. Many internet-supported therapeutic interventions have been developed to supplement in-person treatment. Some of these programs provide a prescriptive online program through a website, which is used by health and mental health information users or patients.

In terms of supporting treatment, IT was most frequently used as a tool for "screening" to assist first-line physicians and identify potential health problems or diseases, such as detecting mild cognitive impairment and diseases at an early stage. The entity "surgery" was also a significant node, which implies that this treatment type is associated with telemedicine in surgery and online counseling for specific diseases. In a network, the "surgery" entity connects not only with "depression" but also disease entities including "cancer," "diabetes," and "breast cancer". "Surgery" also relates to IT entities such as "online," "email," "telephone," and "message." Moreover, the network illustrates that talk therapy is a conventional treatment in the e-mental health research field, as demonstrated by high-frequency entities such as "discussion," "consultation," and "advice".

\section{Common Diseases with IT Entities Network}

In this process, we proposed to investigate the top diseases associated with mental health and identify the IT used for intervention. After the common disease entities with high-frequency detection in the dataset were selected from entity extraction results, the relation extraction results were filtered out. Only the top 20 common diseases and their relations remained for the network analysis. In this report, the numbers in parentheses are the frequency of each disease that was detected in the PMC dataset. The top 20 disease entities were "diabetes (5424)," "cancer (4898)," "smoking cessation (1733)," "dementia (1656)," "blood pressure (1508)," "stroke (1269)," "breast cancer (1200)," "obesity (1198)," "hypertension 
(1132)," "schizophrenia (1088)," "chronic diseases (1080)," “type 2 diabetes (860)," "psychosis (798)," "asthma (739)," "arthritis (714)," "bipolar (697)," "chronic pain (697)," "insomnia (502)," "heart failure (497)," and "anxiety disorders (479)."

The network analysis shows the prominent IT entities related to e-mental health are "online" (weighted degree of 2,478), "measure" (2365), "mobile" (2358), "content" (2242), and "video" (2160) which shown in Table 11. In addition to these examples, there are other IT terms associated with the top diseases that were discovered in the e-mental health dataset. These include privacy and security concerns (informed consent, security), user interface design (interactive, utility, interface user satisfaction, limited English proficiency), as well as hardware and software-related terms. A full list is available via the DOI link; please refer to the Appendix 2. 
Table 11

Top 20 diseases and weighted degree of IT entities

\begin{tabular}{|c|c|c|}
\hline Top 20 common diseases & IT entities & Weighted degree \\
\hline \multirow{5}{*}{$\begin{array}{l}\text { 1. Diabetes } \\
\text { 2. Cancer } \\
\text { 3. Blood pressure } \\
\text { 4. Smoking cessation } \\
\text { 5. Dementia }\end{array}$} & online & 2,478 \\
\hline & measures & 2,365 \\
\hline & mobile & 2,358 \\
\hline & content & 2,242 \\
\hline & video & 2,160 \\
\hline \multirow{4}{*}{$\begin{array}{l}\text { 6. Stroke } \\
\text { 7. Hypertension } \\
\text { 8. Schizophrenia } \\
\text { 9. Obesity }\end{array}$} & interactive & 2,065 \\
\hline & treatment as usual & 1,996 \\
\hline & telephone & 1,946 \\
\hline & mobile phone & 1,905 \\
\hline \multirow{2}{*}{$\begin{array}{l}\text { 10. Chronic diseases } \\
\text { 11. Breast cancer }\end{array}$} & protocol & 1,807 \\
\hline & email & 1,630 \\
\hline \multirow{4}{*}{$\begin{array}{l}\text { 12. Asthma } \\
\text { 13. Psychosis } \\
\text { 14. Bipolar } \\
\text { 15. Heart failure }\end{array}$} & smartphone & 1,562 \\
\hline & website & 1,562 \\
\hline & mobile health & 1,459 \\
\hline & remote & 1,400 \\
\hline \multirow{5}{*}{$\begin{array}{l}\text { 16. Chronic pain } \\
\text { 17. Type } 2 \text { diabetes } \\
\text { 18. Anxiety disorders } \\
\text { 19. Arthritis } \\
\text { 20. Insomnia }\end{array}$} & informed consent & 1,399 \\
\hline & randomized controlled trial & 1,391 \\
\hline & internet & 1376 \\
\hline & text messaging & 1336 \\
\hline & instructions & 1293 \\
\hline
\end{tabular}




\section{Entities Association of Specific Disease Network}

In this section, we deeply investigated the entities and relations of each common disease in the e-mental health research field were analyzed. The analysis focuses on the relations of four entities (disease, symptom, IT, and treatment) to explore what types of IT were used to treat illnesses and their symptoms. The results demonstrate the disease networks with their associated symptoms and the IT used for treatments. For example, the result of the diabetes network shows that signs of "depression" (weighted degree score of 219) occurred most frequently for this disease. The significant technology entities were "measures," "mobile phone," "content," "text messaging," and "smartphone." The technology applications associated with diabetes treatment included "screening," "counseling," "advice," "surgery," and "empowerment." The results show that mental symptoms were found in both physical and mental disorders. The symptom node for "depression" occurred with the highest frequency in every disease. Other symptoms are "phobia" that occurred in the network of diabetes, smoking cessation, stroke, and anxiety disorders, and the symptom entity "insight" (Psychiatric form of awareness of the illness) arose in cancer. More information on the results of all 20 diseases is available at the DOI link; please refer to the Appendix 3.

In this report, we display only the graphs of four mental conditions, including schizophrenia, psychosis, bipolar, and anxiety disorders in Fig. 5 which are adjusted by the weighted degree of entity node for the best view. It visualizes the associated entities of each disease. In the mental disorders networks, the significant symptoms found were "depression," "suicidal thoughts," "suicide attempt," "hyperactivity," and "discharge." The prominent treatment entities include "psychoeducation," and "screening," "suicide prevention." The technology entities frequently associate with "smartphone," "mobile phone," and "online." The IT media entities were also identified repeatedly such as text messaging, email, image, video, and virtual reality as well as social networking. Moreover, The IT for data processing was revealed in these networks (e.g. data mining, machine learning, and streaming). The top five entities for each entity type are shown in Table 12. 
Table 12

Mental diseases with their associated entities

\section{Schizophrenia}

\begin{tabular}{|c|c|c|c|c|c|}
\hline $\begin{array}{l}\text { Symptom } \\
\text { entities }\end{array}$ & $\begin{array}{l}\text { Weighted } \\
\text { degree }\end{array}$ & $\begin{array}{l}\text { Treatment } \\
\text { entities }\end{array}$ & $\begin{array}{l}\text { Weighted } \\
\text { degree }\end{array}$ & IT entities & $\begin{array}{l}\text { Weighted } \\
\text { degree }\end{array}$ \\
\hline depression & 45 & psychoeducation & 4 & smartphone & 57 \\
\hline delusion & 4 & chemotherapy & 4 & mobile & 25 \\
\hline discharge & 2 & skills training & 4 & measures & 24 \\
\hline migraine & 2 & reinforcement & 4 & text messaging & 20 \\
\hline hyperactivity & 2 & screening & 3 & internet & 16 \\
\hline \multicolumn{6}{|l|}{ Psychosis } \\
\hline $\begin{array}{l}\text { Symptom } \\
\text { entities }\end{array}$ & $\begin{array}{l}\text { Weighted } \\
\text { degree }\end{array}$ & $\begin{array}{l}\text { Treatment } \\
\text { entities }\end{array}$ & $\begin{array}{l}\text { Weighted } \\
\text { degree }\end{array}$ & IT entities & $\begin{array}{l}\text { Weighted } \\
\text { degree }\end{array}$ \\
\hline depression & 58 & screening & 6 & online & 44 \\
\hline discharge & 6 & advice & 5 & mobile phone & 19 \\
\hline intoxication & 2 & revision & 5 & clients & 15 \\
\hline intermittent & 2 & psychoeducation & 4 & transition & 14 \\
\hline $\begin{array}{l}\text { suicide } \\
\text { attempt }\end{array}$ & 2 & discussion & 4 & email & 9 \\
\hline \multicolumn{6}{|l|}{ Bipolar } \\
\hline $\begin{array}{l}\text { Symptom } \\
\text { entities }\end{array}$ & $\begin{array}{l}\text { Weighted } \\
\text { degree }\end{array}$ & $\begin{array}{l}\text { Treatment } \\
\text { entities }\end{array}$ & $\begin{array}{l}\text { Weighted } \\
\text { degree }\end{array}$ & IT entities & $\begin{array}{l}\text { Weighted } \\
\text { degree }\end{array}$ \\
\hline depression & 79 & screening & 7 & smartphone & 28 \\
\hline $\begin{array}{l}\text { depressive } \\
\text { episodes }\end{array}$ & 4 & psychoeducation & 6 & mobile & 26 \\
\hline hyperactivity & 3 & surgery & 5 & online & 14 \\
\hline $\begin{array}{l}\text { suicidal } \\
\text { thoughts }\end{array}$ & 3 & $\begin{array}{l}\text { suicide } \\
\text { prevention }\end{array}$ & 5 & streaming & 11 \\
\hline discharge & 2 & measurement & 4 & email & 7 \\
\hline \multicolumn{6}{|c|}{ Anxiety disorders } \\
\hline $\begin{array}{l}\text { Symptom } \\
\text { entities }\end{array}$ & $\begin{array}{l}\text { Weighted } \\
\text { degree }\end{array}$ & $\begin{array}{l}\text { Treatment } \\
\text { entities }\end{array}$ & $\begin{array}{l}\text { Weighted } \\
\text { degree }\end{array}$ & IT entities & $\begin{array}{l}\text { Weighted } \\
\text { degree }\end{array}$ \\
\hline depression & 50 & psychoeducation & 3 & online & 16 \\
\hline
\end{tabular}




\begin{tabular}{|lcllll|}
\hline Schizophrenia & \multicolumn{3}{l|}{} & & \\
\hline phobia & 4 & $\begin{array}{l}\text { suicide } \\
\text { prevention }\end{array}$ & 2 & mobile & 10 \\
\hline insight & 2 & $\begin{array}{l}\text { evaluating } \\
\text { interventions }\end{array}$ & 2 & $\begin{array}{l}\text { cognitive } \\
\text { behavioral therapy }\end{array}$ & 8 \\
\hline acrophobia & 2 & advice & 2 & email & 7 \\
\hline insulin & 2 & $\begin{array}{l}\text { psychological } \\
\text { therapies }\end{array}$ & 2 & audio & 6 \\
\hline
\end{tabular}

Overall of the 20 network graphs of diseases, the treatment nodes are related to online counseling (e.g., email, chat, message, and video) for discussion, advice, shared decision making, meetings, and scheduling as well as patient education, as shown by the nodes for "skills training" and "psychoeducation". Nodes related to medical procedures were also detected, such as "screening," "an intervention of cognitive behavior," "suicide," "relapse," "supportive care," "psychosocial assessment and therapies," "prescription," etc. Other treatment-related nodes identified included "clinical trials" and "obtaining consent".

Specific physical symptoms mainly occurred within a specific disease. For example, diabetes and blood pressure were linked with "insulin," and smoking cessation relates to "chest pain." IT tools were applied for medical procedures to evaluate and diagnose a patient's condition as well as for treatment such as "measuring body mass index," "insulin therapy," "glucose tolerance test," "total cholesterol," "blood glucose monitoring," "heart rate," "diastolic blood pressure," and "systolic blood pressure."

According to the entities and relations of the e-mental health analysis, IT tools were utilized in both physical and psychological interventions and therapies. It was also explicitly used in web-based internet interventions and mobile applications as demonstrated by several of the IT entities (nodes).

\section{Discussion}

\section{E-mental Health Research Clusters and Trends}

In order to overview and understand the scope of the e-mental health research field, we collected WoS bibliographic dataset with the timestamp between 2000 and 2019. We analyzed the trends and observed the related research areas using WoS analysis tools (Clarivate Analytics). We found that the trend of this research field is continually rising and there was significant progress in 2015, many pieces of researches were published and keep the higher rank every year. We deeply investigated the research topics between 2015-2019, we found that the research topic trends associated with various research fields, for example, the e-mental related trends associated with nursing, psychology, medical informatics, computer science, telecommunication, and healthcare innovation. The research trends of the last five years are the internet of things and mobile applications which were focused on mental healthcare. Smart home research topic played in role in digital behavior for mental health intervention. The smartphone-based mental health 
intervention had been studied highly especially for screening, monitoring, diagnosis, and reducing symptoms of depression and anxiety. The mobile health apps were deliberate for digital self-help intervention which allows patients to interact with providers remotely and the physician can deliver therapy. In 2019, we found that research-related artificial intelligence (Al) such as brain-computer interfaces was concerned more in this research field.

We further applied co-citation network analysis to explore the significant e-mental health research clusters which were developed in this research area between 2015-2019. The finding demonstrated that among 10,834 papers, there are 16 clusters belong to the e-mental health research field. The biggest cluster is mentioned to depression which is a mental symptom and disease. Other signs and sicknesses also were discovered include smoking cessation, obesity, cancer, and psychosis which are linked to mental illness, such as quitting smoking associates with an increased risk of depression [56, 57]. Moreover, cluster-related health information technology was established in this research area that comprises mhealth, health literacy, telehealth, health information, and self-management. In addition, the visualization shows the cluster-related application design as shown in the clusters of usability testing and artificial intelligence. Other clusters in this finding, we presumed that are correlated to a target demographic for e-mental health (older adults and MSM clusters).

According to data analysis results, we could overview the hidden e-mental health research clusters and predicted the research trends from the top terms and highest citation year. At the beginning of this research field (2008-2010), it was associated with cancer survivors and older adults. This states that the first intention of e-mental health research focused on the use of IT for self-management as well as for mitigation of mental health impacts of the physical sickness. In 2012, the research tended to focus on digital mental health intervention related to psychological and lifestyle intervention as shown as the biggest cluster as "depression" which presented the top terms of mental health and behavioral therapy. This observation is confirmed by research cluster "physical activity" and "psychosis" which obtained high citation in the same year. In the timespan of 2013-2015, health information and literacy were awareness in this research field. Telemedicine was studied for mental health education and mental condition prevention, as well as mobile apps. Moreover, in 2015, Al became exciting as the mental health digital solution which was interpreted by the cluster and top terms of "artificial intelligence," "deep learning," and "medical informatics". In the existing studies, many pieces of research utilized Al to treat and reduce the burden of mental sickness [58-61].

\section{IT and Biomedical Entities and Relations Network Analysis}

To understand diseases, symptoms, treatments, and IT in e-mental health studies. We used an information extraction system that integrates dictionary-based entity extraction and rule-based relation extraction. This process detected entities and identify the associations between biomedical and IT entities. The overview shows that the significant entities are depression symptoms, the common diseases including cancer and diabetes, the IT of mobile, online, measures, and content, and the treatments relate to screening, surgery, and discussion. 
By considering the betweenness weight degree, the major associations in the network are depressiondiabetes, depression-cancer, depression-online, depression-mobile, and depression-measures. This result indicates that e-mental health researches mostly focused on depression as a main mental condition and it is connected with diabetes and cancer sickness. Previous studies [62-64] verified that diabetes patients have a higher chance of developing depression due to the rigors of managing diabetes, which can often adversely affect the quality of life as well as in case of cancer patients, previous studies revealed that cancer is often associated with depression disorder as a result of anxiety about the illness as well as the pain and fatigue symptoms [65-67]. Therefore, we can describe that the key components of the use of IT are the online and mobile devices which commonly utilized for mental health prevention.

\section{The uses of IT in e-mental health}

After extracting the diseases entity we found that there are 2,765 disease names include physical and mental diseases were detected in the dataset which confirmed that in the studies of e-mental health, the physical condition was also concerned. For examining the uses of IT, we took the top 20 diseases to visualize the related IT in e-mental health. The finding shows 283 IT entities names which are described in four major groups including multimedia, information system, programming, and disease management and therapy. First, multimedia refers to a type of content and media used in e-mental health as shown by related entities such as video, email, website, text message, virtual, games, video conferencing, and clinical trials. Moreover, the devices mentioned in the data corpus were a smartphone, monitor, android, sensor, tablet, mobile devices, and iPhone.

Secondly, the information systems deliver and support users with the information needed for their activities effectively and efficiently. The related entities include information security, clinical decision support system, information systems, information and communication technologies, health information systems, computerized decision support, and personal health management. Next, programming is the development of a set of instructions for a computer to perform a task. The results include the following nodes related to programming: algorithm, analysis of variance (ANOVA), query, segment, machine learning, least squares, embedded, and data mining.

Lastly, disease management and therapy refer to a system that coordinates healthcare interventions and communications. The following IT entities associated with disease management and therapy: measures, treatment as usual, instructions, disease management, hivaids, body mass index, cognitive behavioral therapy, heart rate, cardiac rehabilitation, remote monitoring, real-time, case management, interactive voice response, diagnostics, clinical practice guidelines, emergency room, behavior change techniques, health-related quality of life (HRQOL), test of functional health literacy in adults (TOFHLA), and more.

Consequently, we could explain that the uses of IT in e-mental health care were developed and provided for healthcare providers and people who have mental illness and people who are physically sick such as diabetes and cancer that can cause mental disorders, for physical treatment, mental screening, and prevention. For example, people who inject themselves with medication, such as people with diabetes who require insulin, are affected by trypanophobia (needle phobia), which requires collaboration between 
psychological medicine and diabetes teams [68]. Cigarette smoking can cause social phobia and anxiety disorder [69-70]. People who live with chronic pain take a risk of suicide [71-72]. In contrast, the IT was utilized for mental disorders patients who may take a risk of physical difficulties such as elderly people who have a history of bipolar disorder have a significant risk of developing dementia [73], major depressive and bipolar disorder can lead to accelerated atherosclerosis and early cardiovascular disease in adolescence[74]. Some IT devices were used for specific diseases and symptoms such as high blood pressure, which can affect mood disorders [75-76], and low blood pressure associates with suicidal ideation [77].

According to the entities and relations analysis in e-mental health research papers, we could describe the connection of physical and mental illness and the uses of related IT for specific diseases, symptoms, and treatments.

\section{Limitation}

We acknowledge that our study has a limitation of the use of a dictionary for entity extraction since the text mining tools integrate dictionary-based to automatically tag bio-entities according to their types. In our method, we relied on MeSH and SNOMED terms for developing our dictionaries for the information extraction system. However, there was an error performed on the incorrectly labeled entities, especially the type of diseases and symptoms which some terms could be either a disease name or a symptom. For instance, the labeling of "blood pressure" and "smoking cessation" as diseases (Table 10) and "discharge" "insulin," and "insight," as symptoms (Table 11). These errors came from ambiguous concepts of an entity and sometimes it happened because of a lexical error that the system failed to extract the entire entity. For example, quitting smoking can lead to symptoms of nicotine withdrawal such as depression, anxiety, and irritability. Therefore a smoking cessation was identified as a disease. At the same time, depression, anxiety, and irritability could be mental diseases or mental symptoms.

Dictionaries and rules-based NER is the classical method that linguists manually create the specific rule or special dictionaries according to the characteristics of data sets. However, the diversity and ambiguity of named entity representations bring great challenges to the understanding of natural language. Under different cultures, domains, and backgrounds, the denotations of named entities are different, which is the fundamental problem that named entity recognition technology needs to solve. After obtaining a large amount of text data, due to different granularity of knowledge representation, different degrees of confidence, lack of normative constraints, and other problems, various expressions and unclear references of named entities appear. Therefore, it is necessary to fully understand the context semantics to dig deep into the entity semantics for recognition.

In future work, deep learning will be applied in NER, transfer learning versus remote supervised learning are fully utilized to solve the problem of named entity identification in resource-poor areas and reduce the workload of manual annotation. 


\section{Conclusion}

This paper utilized bibliometric and information extraction methods to report on the landscape of the emental health research field and the use of IT for mental health treatments. The data on the topic of emental health was obtained from WoS and PMC. WoS and Citespace were used as tools to identify research trends and for cluster analysis. The PKDE4J tool was utilized for the IT and biomedical information extraction, which combined the entities of diseases, symptoms, and treatments. Then, the results of the entities and relations compilation were processed via network analysis, and this was visualized using the Gephi tool.

The results indicate that e-mental health research has been increasing, and most studies relate to health care sciences services and medical informatics. The research is comprised of 16 clusters, which include ehealth, diseases, IT, and self-management. Additionally, entities for IT, diseases, symptoms, and treatments and their connections were illustrated in network graphs. The most frequently occurring entity was IT, which was categorized as a mobile entity. Relation extraction showed that the most frequent entity association was depression paired with cancer, diabetes, mobile, online, measures, and screening. Overall, the data shows that e-mental health research focused on studying disease-related depression, suicidal thoughts, and suicide attempts and using IT, primarily via online and mobile devices to deliver the media such as health content, text messaging, and audio, to screening, psychoeducation, advice, and suicide prevention.

The results of this study are useful to understand the research clusters and the research trends for emental health, which can support researchers in developing a survey in this field. It would also be beneficial for physicians, patients, and their proximal family members to understand and optimally treat patients with mental disorders in both physical and psychological therapy modalities using IT. The use of IT supports physicians to deliver psychological services as well as health promotion, and at the same time, the patients can have accessibility and flexibility for self-monitoring integrated into treatment. In addition, healthcare providers and IT developers could use the data in this study to support e-mental health design. Furthermore, the outcomes of the entity and relation extraction could be utilized for disease prevention since they identify the diseases that could potentially cause mental health problems.

We expected that our findings would increase the researcher's understanding of E-mental health and related research area, and the use of IT for healthcare that would support the information for the health researchers to develop better devices and approaches. Moreover, it would promote widely different disciplines especially emerging research fields such as medical informatics and Al.

\section{Abbreviations}

E-mental: electronic mental health care

ICT: information and communication technology 
IT: information technology

IE: information extraction

NLP: natural Language Processing

NER: named Entity Recognition

RE: relation Extraction

WoS: Web of science

PMC: PubMed Central

HRQoL: health-related quality of life

TOFHLA: test of functional health literacy in adults

Mhealth: mobile health

MSM: sex with men

CBT: cognitive-behavioral therapy

TAU: treatment as usual

RCT: randomized controlled trial

\section{Declarations}

Funding

This work was supported by the Ministry of Education of the Republic of Korea and the National Research Foundation of Korea (NRF-2020S1A5B1104865).

\section{Conflicts of interest}

The authors declare that they have no competing interests.

\section{Availability of data and materials}

Appendix 1: E-mental health research knowledge

clusters.https://doi.org/10.6084/m9.figshare.12362522.v2 
Appendix 2: The top 20 diseases with the IT used in e-mental health (283 entity names).https://doi.org/10.6084/m9.figshare.12254324.v2

Appendix 3: Top 20 Disease entities and relations in e-mental health. https://doi.org/10.6084/m9.figshare.12271622.v2

\section{Code availability}

Not applicable

\section{Authors'Contributions}

Tatsawan Timakum: conceptualization, data curation, formal analysis, investigation, methodology, project administration, resources, software, visualization, writing-original draft, writing-review \& editing.Qing Xie: data curation, formal analysis, investigation, methodology, software, visualization, writing-original draft,writing-review \& editing.Min Song: conceptualization, formal analysis, funding acquisition, investigation, methodology, project administration, resources, software, supervision, writingoriginal draft, writing-review \& editing.

\section{Ethics approval}

Not applicable

\section{Consent to participate}

Not applicable

\section{Consent for publication}

Not applicable

\section{References}

1. Salleh MR.: Life event, stress and illness. MJMS. 15(4), 92008 (2008).

2. Castillo EG, ljadi-Maghsoodi R, Shadravan S, Moore E, Mensah MO, Docherty M, Nunez MG, Barcelo $\mathrm{N}$, Goodsmith N, Halpin LE, Morton I.: Community interventions to promote mental health and social equity. Current psychiatry reports(2019). https://doi.org/10.1007/s11920-019-1017-0.

3. :Mental health services: the demand challenge. https://nhsproviders.org/mental-health-servicesaddressing-the-care-deficit/the-demand-challenge.Accessed 28 April 2020. 
4. Gilburt, H.:Mental health under pressure.

https://www.kingsfund.org.uk/sites/default/files/field/field_publication_file/mental-health-underpressure-nov15_0.pdf.Accessed 28 April 2020.

5. Newman MG, Szkodny LE, Llera SJ, Przeworski A.: A review of technology-assisted self-help and minimal contact therapies for drug and alcohol abuse and smoking addiction: is human contact necessary for therapeutic efficacy?. Clinical psychology review(2011). https://doi.org/10.1016/j.cpr.2010.10.002.

6. Bennion MR, Hardy G, Moore RK, Millings A.: E-therapies in England for stress, anxiety or depression: what is being used in the NHS? A survey of mental health services. BMJ open(2017).https://doi.org/10.1136/bmjopen-2016-014844.

7. Griffiths KM, Farrer L, Christensen $H .:$ The efficacy of internet interventions for depression and anxiety disorders: a review of randomised controlled trials. Medical Journal of Australia(2010).https://doi.org/10.5694/j.1326-5377.2010.tb03685.x.

8. Van Der Krieke L, Wunderink L, Emerencia AC, De Jonge P, Sytema S.: E-mental health selfmanagement for psychotic disorders: State of the art and future perspectives. Psychiatric Services(2014).https://doi.org/10.1176/appi.ps.201300050.

9. Riper H, Andersson G, Christensen H, Cuijpers P, Lange A, Eysenbach G.: Theme issue on e-mental health: a growing field in internet research. Journal of medical Internet research(2010). https://doi.org/10.2196/jmir.1713.

10. Meyer B, Berger T, Caspar F, Beevers C, Andersson G, Weiss M.: Effectiveness of a novel integrative online treatment for depression (Deprexis): randomized controlled trial. Journal of medical Internet research(2009).https://doi.org/10.2196/jmir.1151.

11. Christensen, H.:E-mental health.https://www.blackdoginstitute.org.au/research/key-researchareas/emental-health. Accessed 28 April 2020.

12. National Institute of Mental Health.: Technology and the Future of Mental Health Treatment.https://www.nimh.nih.gov/health/topics/technology-and-the-future-of-mental-healthtreatment. Accessed 23 May 2021.

13. Van Straten A, Cuijpers P, Smits N.: Effectiveness of a web-based self-help intervention for symptoms of depression, anxiety, and stress: randomized controlled trial. Journal of medical Internet research(2008). https://doi.org/10.2196/jmir.954.

14. Griffiths KM, Calear AL, Banfield M.: Systematic review on Internet Support Groups (ISGs) and depression (1): Do ISGs reduce depressive symptoms?. Journal of medical Internet research(2009).https://doi.org/10.2196/jmir.1270.

15. Riper H, Kramer J, Keuken M, Smit F, Schippers G, Cuijpers P.: Predicting successful treatment outcome of web-based self-help for problem drinkers: secondary analysis from a randomized controlled trial. Journal of Medical Internet Research(2008).https://doi.org/10.2196/jmir.1102.

16. Takahashi Y, Uchida C, Miyaki K, Sakai M, Shimbo T, Nakayama T.: Potential benefits and harms of a peer support social network service on the internet for people with depressive tendencies: qualitative 
content analysis and social network analysis. Journal of medical Internet research (2009). https://doi.org/10.2196/jmir.1142.

17. Yang, Y.N., Zhang, Y.D., Huang, W.T., Xie, H.M., Chen, J.L., Cai, C.Y.:Knowledge mapping of Building information modelling research í A visual analysis using CiteSpace. In:Proceedings of 22nd International Conference on Advancement of Construction Management and Real Estate, pp. 612619.CRIOCM 2017 (2019).

18. Zhang X, Estoque RC, Xie H, Murayama Y, Ranagalage M.: Bibliometric analysis of highly cited articles on ecosystem services. PloS one(2019). https://doi.org/10.1371/journal.pone.0210707.

19. Leefmann J, Levallois C, Hildt E.: A bibliometric analysis of the guiding themes of an emerging research field. Frontiers in human neuroscience(2016). https://doi.org/10.3389/fnhum.2016.00336.

20. He, S., Zhao, Y., Fan, Y., Zhao, X., Yu, J., Xie, J., Wang, C., Su, J.:Research trends and hotspots analysis related to monocarboxylate transporter 1: A study based on bibliometric analysis. Int. J. Environ. Res. Public Health(2019). https://doi.org/10.3390/ijerph16071091.

21. Saheb, T., Saheb, M.:Analyzing and visualizing knowledge structures of health informatics from 1974 to 2018: A bibliometric and social network analysis (2019). https://doi.org/10.4258/hir.2019.25.2.61.

22. Raghupathi, W., Nerur, S.:Research themes and trends in health information systems. Methods Inf. (2008). https://doi.org/10.3414/ME0516.

23. Shen, L., Xiong, B., Li, W., Lan, F., Evans, R., Zhang, W.:Visualizing collaboration characteristics and topic burst on international mobile health research: Bibliometric analysis. JMIR mHealth uHealth(2018). https://doi.org/10.2196/mhealth.9581.

24. Gu, D., Li, T., Wang, X., Yang, X., Yu, Z.:Visualizing the intellectual structure and evolution of electronic health and telemedicine research. Int. J. Med. (2019).

https://doi.org/10.1016/j.ijmedinf.2019.08.007.

25. Singh S.: Natural language processing for information extraction. arXiv preprint arXiv:1807.02383. 6 Jul 2018.

26. Song, M., Baek, S.H., Heo, G.E., Lee, J.H.:Inferring drug-protein-side effect relationships from biomedical text. Genes (Basel) (2019). https://doi.org/10.3390/genes10020159.

27. Song, M., Kang, K., Young An, J.:Investigating drug-disease interactions in drug-symptom-disease triples via citation relations. J. Assoc. Inf. Sci. (2018). https://doi.org/10.1002/asi.24060.

28. Zhu, Y., Song, M., Yan, E.:Identifying liver cancer and its relations with diseases, drugs, and genes: A literature-based approach. PLoS One(2016).https://doi.org/10.1371/journal.pone.0156091.

29. Xu, R., Wang, Q.Q.:Large-scale extraction of accurate drug-disease treatment pairs from biomedical literature for drug repurposing. BMC Bioinformatics(2013). https://doi.org/10.1186/1471-2105-14181.

30. Rindflesch, T.C., Tanabe, L., Weinstein, J.N., Hunter, L.:EDGAR: Extraction of Drugs, Genes And Relations from the Biomedical Literature. (1999). https://doi.org/10.1142/9789814447331_0049. 
31. Scott, J., Carrington, P., Marin, A., Wellman, B.:Social Network Analysis: An Introduction. In: The SAGE Handbook of Social Network Analysis (2015). https://doi.org/10.4135/9781446294413.n2.

32. Newman, M.:Networks: An Introduction(2010). https://doi.org/10.1093/acprof:oso/9780199206650.001.0001.

33. Pappi, F.U., Scott, J.:Social Network Analysis: A Handbook. Contemp. Sociol. (1993)https://doi.org/10.2307/2075047.

34. Song, M., Heo, G.E., Lee, D.:Identifying the landscape of Alzheimer's disease research with network and content analysis. Scientometrics(2015). https://doi.org/10.1007/s11192-014-1372-x.

35. Opsahl, T., Agneessens, F., Skvoretz, J.:Node centrality in weighted networks: Generalizing degree and shortest paths. Soc. Networks(2010). https://doi.org/10.1016/j.socnet.2010.03.006.

36. Lu, L., Zhang, M.:Edge betweenness centrality. In: Encyclopedia of systems biology. pp. 647648(2013).

37. Chen C.:CiteSpace: a practical guide for mapping scientific literature. Hauppauge, NY: Nova Science Publishers (2016).

38. Song, M., Kim, W.C., Lee, D., Heo, G.E., Kang, K.Y.: PKDE4J: Entity and relation extraction for public knowledge discovery. J. Biomed. Inform. (2015). https://doi.org/10.1016/j.jbi.2015.08.008.

39. Barlow JH, Ellard DR, Hainsworth JM, et al: A review of self-management interventions for panic disorders, phobias and obsessive-compulsive disorders. Acta Psychiatrica Scandinavica 111, 272285 (2005).

40. National Center for Biotechnology Information.: Medical Subject

Headings.https://www.ncbi.nlm.nih.gov/mesh. Accessed 20 April 2020.

41. : SNOMED International determines global standards for health terms.http://www.snomed.org/. Accessed 20 April 2020.

42. : The Computer Dictionary.https://techterms.com/browse/. Accessed 20 April 2020.

43. : Computer terms, dictionary, and glossary. https://www.computerhope.com/jargon.htm. Accessed 20 April 2020.

44. Bodenreider, O.: The Unified Medical Language System (UMLS): Integrating biomedical terminology. Nucleic Acids Res. 32, (2004). https://doi.org/10.1093/nar/gkh061.

45. : The Open Graph Viz Platform. https://gephi.org/. Accessed 20 April 2020.

46. Safran, C., Goldberg, H.: Electronic patient records and the impact of the Internet. Int. J. Med. (2000). https://doi.org/10.1016/S1386-5056(00)00106-4.

47. Eysenbach G.: Towards ethical guidelines for e-health: JMIR theme issue on eHealth ethics. Journal of Medical Internet Research (2000).https://doi.org/10.2196/jmir.2.1.e7.

48. Norman CD, Skinner HA. eHealth literacy: essential skills for consumer health in a networked world. Journal of medical Internet research (2006). https://doi.org/10.2196/jmir.8.2.e9.

49. Islam, S.M.R., Kwak, D., Kabir, M.H., Hossain, M., Kwak, K.S.: The internet of things for health care: A comprehensive survey. IEEE Access. https://doi.org/10.1109/ACCESS.2015.2437951. 
50. Stoyanov, S.R., Hides, L., Kavanagh, D.J., Zelenko, O., Tjondronegoro, D., Mani, M.: Mobile App Rating Scale: A New Tool for Assessing the Quality of Health Mobile Apps. JMIR mHealth uHealth (2015). https://doi.org/10.2196/mhealth.3422.

51. Saeb, S., Zhang, M., Karr, C.J., Schueller, S.M., Corden, M.E., Kording, K.P., Mohr, D.C.: Mobile phone sensor correlates of depressive symptom severity in daily-life behavior: An exploratory study. J. Med. Internet Res.(2015). https://doi.org/10.2196/jmir.4273.

52. Tennant, B., Stellefson, M., Dodd, V., Chaney, B., Chaney, D., Paige, S., Alber, J.: eHealth literacy and Web 2.0 health information seeking behaviors among baby boomers and older adults. J. Med. Internet Res. (2015). https://doi.org/10.2196/jmir.3992.

53. Nicholas, J., Larsen, M.E., Proudfoot, J., Christensen, H.: Mobile apps for bipolar disorder: A systematic review of features and content quality. J. Med. Internet Res. (2015). https://doi.org/10.2196/jmir.4581.

54. Maddison, R., Rawstorn, J.C., Stewart, R.A.H., Benatar, J., Whittaker, R., Rolleston, A., Jiang, Y., Gao, L., Moodie, M., Warren, I., Meads, A., Gant, N.: Effects and costs of real-time cardiac telerehabilitation: Randomised controlled non-inferiority trial. Heart (2019). https://doi.org/10.1136/heartjnl-2018313189.

55. Freeman, L. C.: A set of measures of centrality based on betweenness. Sociometry(1977). https://doi:10.2307/3033543.

56. Breslau N., Johnson EO.: Predicting smoking cessation and major depression in nicotine-dependent smokers. American Journal of Public Health. 90(7), 1122 (2000).

57. Glassman AH., Covey LS., Stetner F., Rivelli S.: Smoking cessation and the course of major depression: a follow-up study. The Lancet. 357(9272), 1929-32 (2001).

58. Prochaska J.J., Vogel E.A., Chieng A., Kendra M., Baiocchi M., Pajarito S., Robinson A.: A Therapeutic Relational Agent for Reducing Problematic Substance Use (Woebot): Development and Usability Study. J. Med. Internet Res. (2021). https://doi:10.2196/24850

59. Carr S.: 'Al gone mental': engagement and ethics in data-driven technology for mental health. Journal of Mental Health (2020). https://doi.org/10.1080/09638237.2020.1714011

60. Chen I.Y., Szolovits P., Ghassemi M.: Can Al help reduce disparities in general medical and mental health care?. AMA journal of ethics. (2019). http://doi.org/10.1001/amajethics.2019.167.

61. Graham S., Depp C., Lee E.E., Nebeker C., Tu X., Kim H.C., Jeste D.V.: Artificial intelligence for mental health and mental illnesses: an overview. Current psychiatry reports (2019). https://doi.org/10.1007/s11920-019-1094-0.

62. Castro, M.R.:Diabetes and depression: Coping with the two conditions.https://www.mayoclinic.org/diseases-conditions/diabetes/expert-answers/diabetes-anddepression/faq-20057904. Accessed 20 April 2020.

63. Egede LE, Ellis C.: Diabetes and depression: global perspectives. Diabetes research and clinical practice (2010). https://doi.org/10.1016/j.diabres.2010.01.024. 
64. Van Bastelaar, K.M.P., Pouwer, F., Cuijpers, P., Riper, H., Snoek, F.J.: Web-based depression treatment for type 1 and type 2 diabetic patients: A randomized, controlled trial. Diabetes Care (2011). https://doi.org/10.2337/dc10-1248.

65. Spiegel D, Giese-Davis J.: Depression and cancer: mechanisms and disease progression. Biological psychiatry (2003). https://doi.org/10.1016/S0006-3223(03)00566-3.

66. Couper, J.W., Pollard, A.C., Clifton, D.A.: Depression and cancer. Med. J. Aust. (2013). https://doi.org/10.7748/cnp.6.9.10.s11.

67. Pitman, A., Suleman, S., Hyde, N., Hodgkiss, A.: Depression and anxiety in patients with cancer. BMJ. (2018). https://doi.org/10.1136/bmj.k1415.

68. Green, L., Feher, M., Catalan, J.: Fears and phobias in people with diabetes. Diabetes. Metab. Res. Rev. (2000). https://doi.org/10.1002/1520-7560(2000)9999:9999<::AID-DMRR123>3.0.C0;2-T.

69. McCabe, R.E., Chudzik, S.M., Antony, M.M., Young, L., Swinson, R.P., Zolvensky, M.J.: Smoking behaviors across anxiety disorders. J. Anxiety Disord. (2004). https://doi.org/10.1016/j.janxdis.2003.07.003.

70. Dahne, J., Hise, L., Brenner, M., Lejuez, C.W., MacPherson, L.: An experimental investigation of the functional relationship between social phobia and cigarette smoking. Addict. Behav. (2015). https://doi.org/10.1016/j.addbeh.2014.12.012.

71. Hooley JM, Franklin JC, Nock MK.: Chronic pain and suicide: understanding the association. Current pain and headache reports(2014). https://doi.org/10.1007/s11916-014-0435-2.

72. Racine M.: Chronic pain and suicide risk: A comprehensive review. Progress in NeuroPsychopharmacology and Biological Psychiatry (2018).https://doi.org/10.1016/j.pnpbp.2017.08.020.

73. Diniz, B.S., Teixeira, A.L., Cao, F., Gildengers, A., Soares, J.C., Butters, M.A., Reynolds, C.F.: History of Bipolar Disorder and the Risk of Dementia: A Systematic Review and Meta- (2017). https://doi.org/10.1016/j.jagp.2016.11.014.

74. Goldstein B.I., Carnethon M.R., Matthews K.A., McIntyre R.S., Miller G.E., Raghuveer G., Stoney C.M., Wasiak H., McCrindle B.W.: Major depressive disorder and bipolar disorder predispose youth to accelerated atherosclerosis and early cardiovascular disease: a scientific statement from the American Heart Association. Circulation (2015). https://doi.org/10.1161/CIR.0000000000000229.

75. American heart association.: Common high blood pressure meds affect mood disorders. https://newsarchive.heart.org/common-high-blood-pressure-meds-affect-mood-disorders/. Accessed 20 April 2020.

76. Bacon S.L., Campbell T.S., Arsenault A., Lavoie K.L.: The impact of mood and anxiety disorders on incident hypertension at one year. International Journal of Hypertension (2014). https://doi.org/10.1155/2014/953094.

77. Joung, K.I., Cho, S. : Association of low blood pressure with suicidal ideation: A cross-sectional study of 10,708 adults with normal or low blood pressure in Korea. BMC Public Health (2018). https://doi.org/10.1186/s12889-018-5106-5. 
Figures
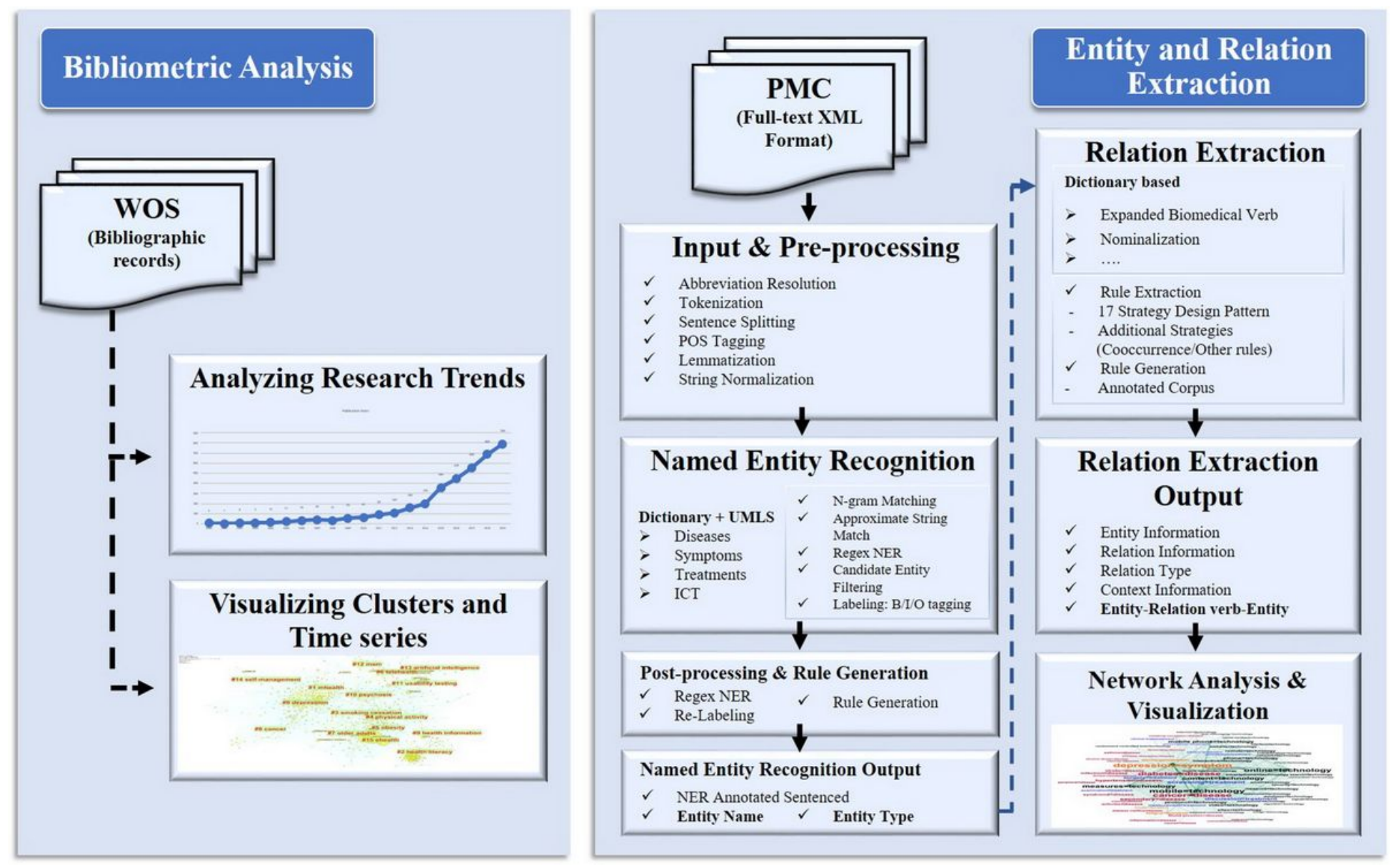

Figure 1

Research framework

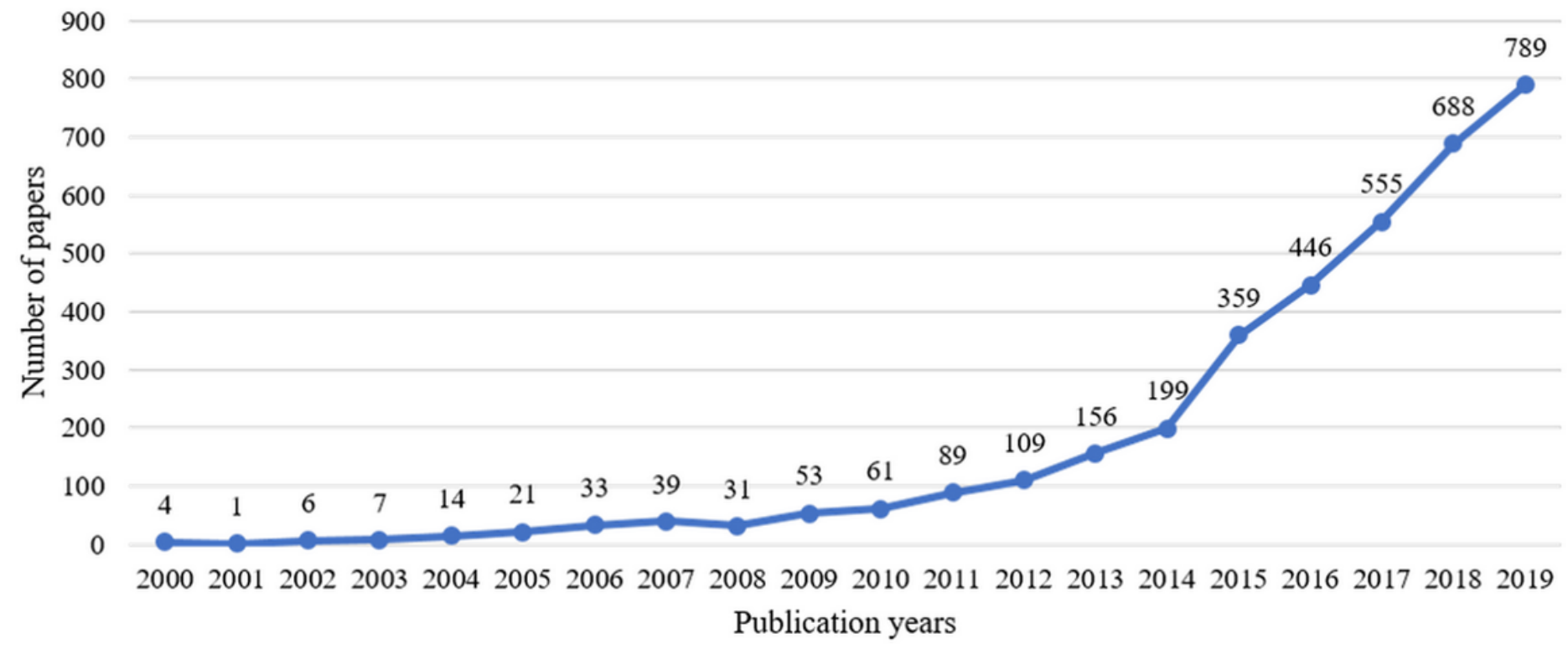

Figure 2 
Number of published papers related to e-mental health between 2000 and 2019, indexed by the Clarivate Analytics tools

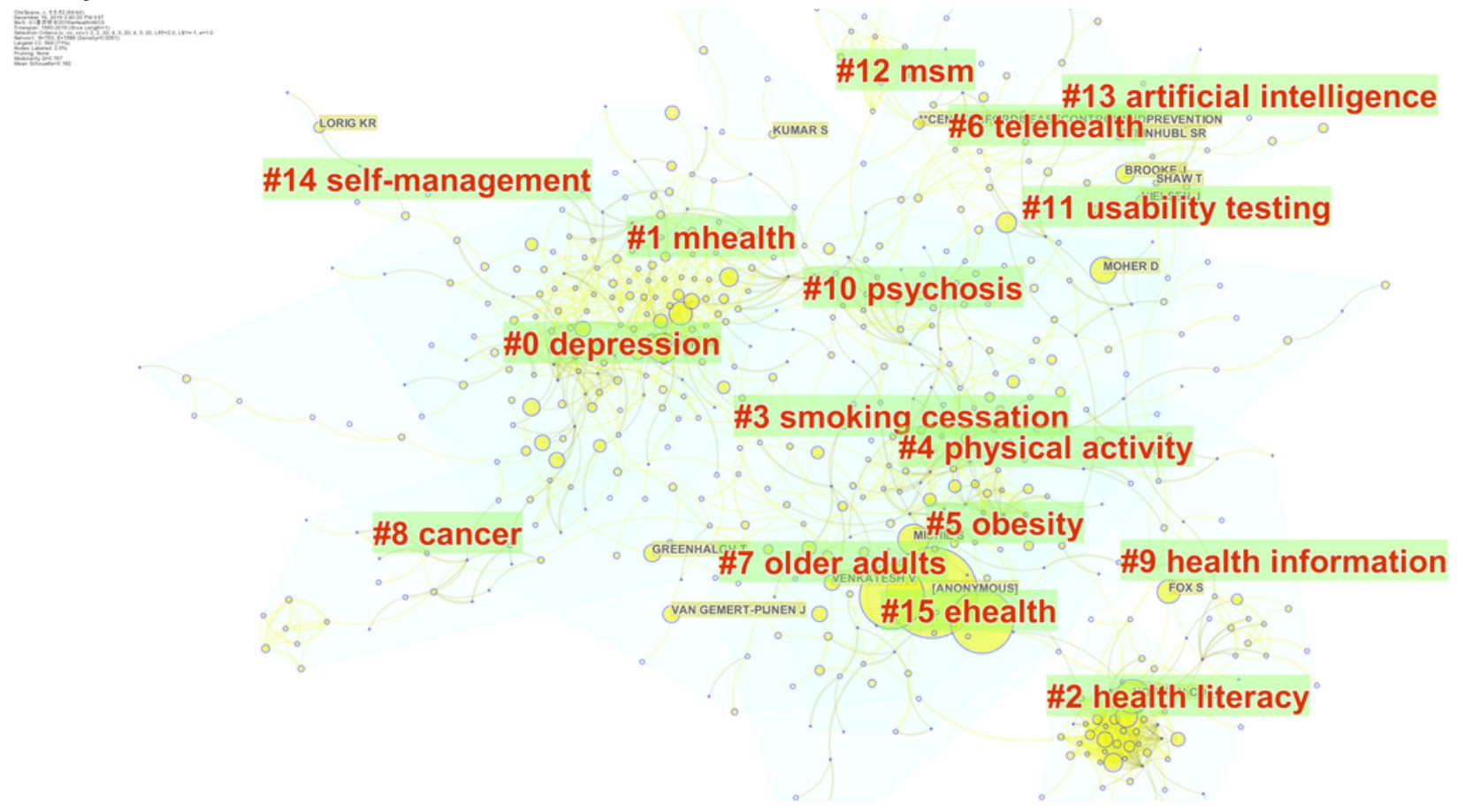

\section{Figure 3}

E-mental health care research clusters 


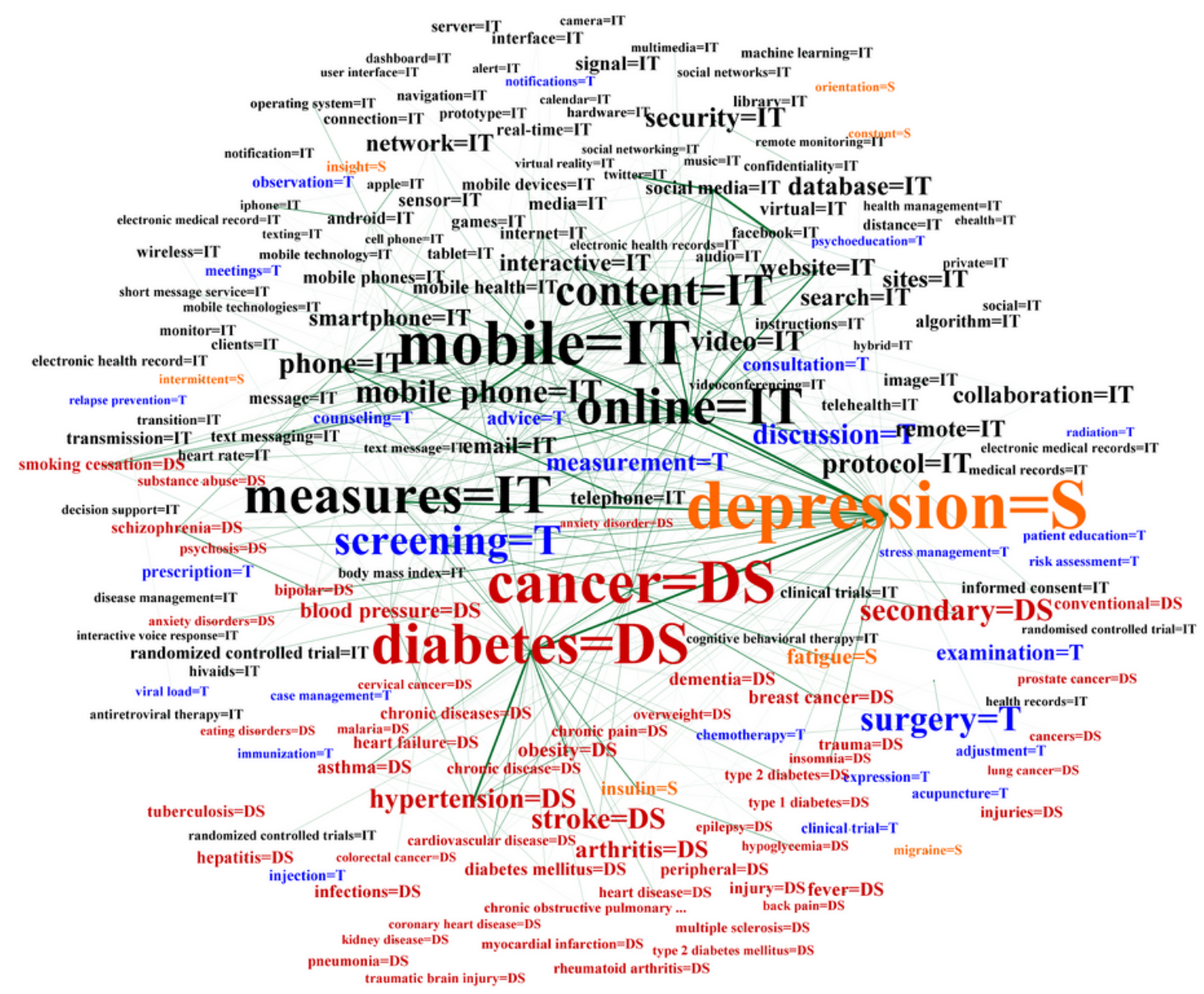

Figure 4

Network of entities and relations in the e-mental health research field 

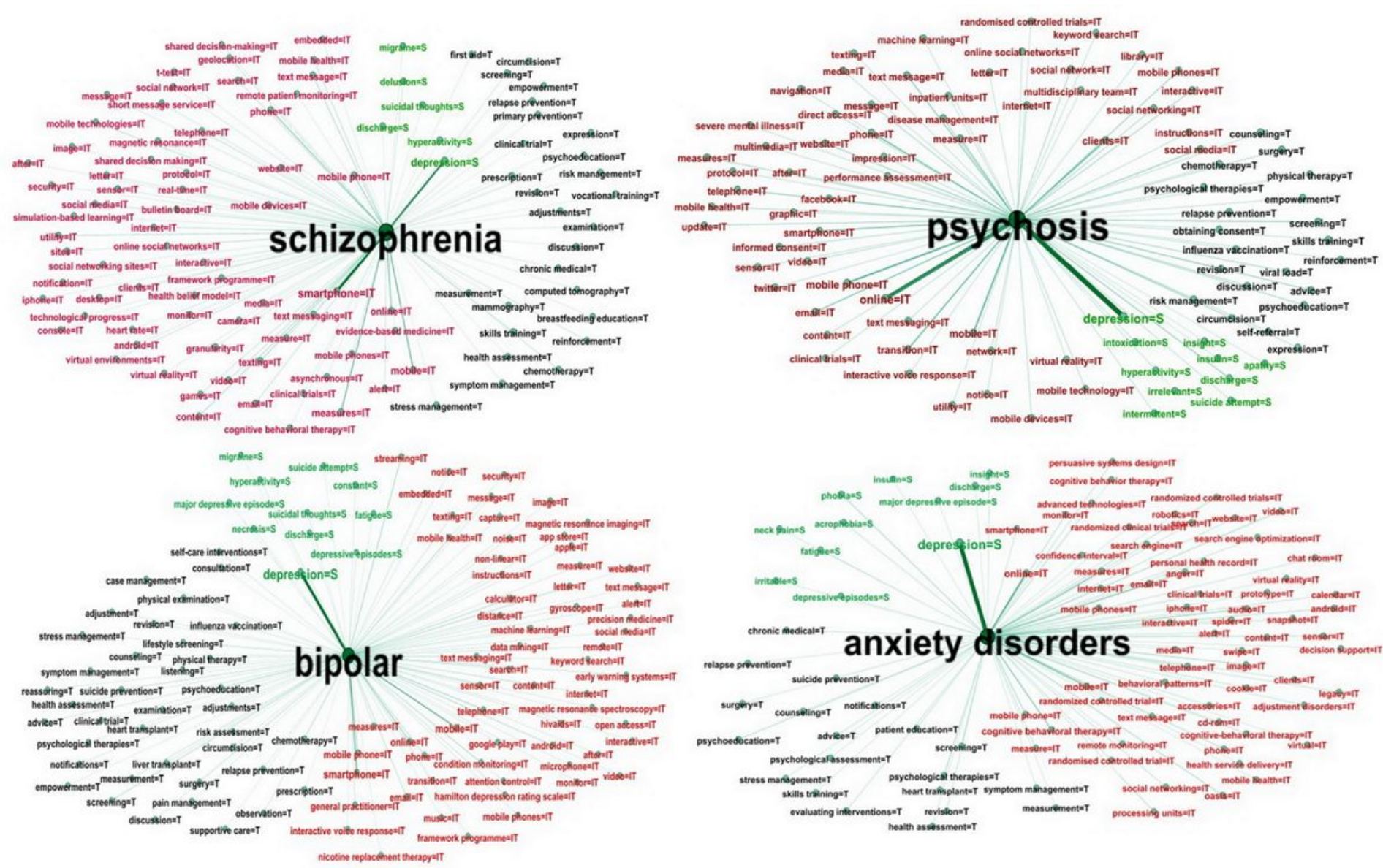

Figure 5

Entity Association network for mental disorders

\section{Supplementary Files}

This is a list of supplementary files associated with this preprint. Click to download.

- Appendix1Ementalhealthresearchknowledgeclusters.docx

- Appendix2Thetop20diseaseswiththelTused.docx

- Appendix3Top20Diseaseentitiesandrelationships.docx 